\title{
ROLE OF SALINITY IN PRECIPITATION AND WELL WATER DEPTH RELATIONSHIP
}

\author{
Manoj K. Jha \\ Department of Civil, Architectural and Environmental Engineering, \\ North Carolina A and T State University, NC 27411, Greensboro, USA
}

Received 2013-04-12; Revised 2013-07-16; Accepted 2014-02-15

\begin{abstract}
Excessive groundwater pumping can decrease the amount of fresh water flowing towards the coastal discharge areas, allowing salt water to be drawn into the fresh water zones of coastal aquifers. This process gets complicated with the frequent change behavior of groundwater levels in observation wells. The fluctuation happens due to various reasons but can be directly correlated with the precipitation patterns. We hypothesized that the salinity of water adds to the complexity and affects the causal relationship between precipitation and well water depth. Relevant data (precipitation, well water depth and water salinity) were collected for analysis from a monitoring site located in North Carolina. Analytical study of mean monthly data identified the lack of a strong correlation between the water table depth and precipitation. Moreover, the salinity was found to be slightly correlated with precipitation. A significant correlation was expected between the precipitation and well water depth and salinity should have been more closely related to the precipitation. The lack of correlation is mainly attributed to the lack of available daily data, especially in the case of salinity.
\end{abstract}

Keywords: Salinity, Precipitation, Well Water Depth, Correlation

\section{INTRODUCTION}

Today many areas of the world are facing a shortage of water supply due to droughts and problems related to losses in the water supply system. It will continue to rise in the future under rapidly growing population, urbanization and uncertainty with the impacts of climate change. The water shortage has led part of the population to look for additional water supply by drilling private and public wells. One of the major factors of the water shortage is the increase of urbanization of coastal areas which is causing a decrease in the natural recharge of aquifers. This overexploitation condition increases the risk of seawater intrusion and causes the aquifer system to be under a severe threat of degradation (Montenegro et al., 2003). Many groundwater basins have limited ability to get rid of their excess salt. Additional salt accumulates in the soil over time reducing the agricultural utility of the soil. High salinity has many adverse impacts on the use of groundwater resources.
Fresh water has a lower specific density than salt water so it will float on top. The boundary between the salt water and fresh water is not very clear but there exists a zone of dispersion where the salt water and fresh water mix. Typically, groundwater will flow from areas with higher groundwater levels to areas with lower groundwater levels. This natural movement of fresh water towards the sea prevents salt water from entering freshwater coastal aquifers. Excessive groundwater pumping can decrease the amount of fresh water flowing towards the coastal discharge areas, allowing salt water to be drawn into the fresh water zones of coastal aquifers. This extra pumping can cause problems especially in coastal areas where the pumping of the fresh water aquifer creates a pressure vacuum which can draw salt water from the ocean to mix with the aquifer.

These challenges can be met by using new methods to increase alternative water sources, including recycled water and storm water. Although the scientific community is encouraging and supporting the increased reuse of discharge water and storm 
water, there are concerns about salt and nutrient loading of groundwater basins as a result of these activities (Montenegro et al., 2003).

The main key to controlling saltwater intrusion is to maintain the proper balance between water being pumped from an aquifer and the amount of water recharging it (Xue et al., 1993). Constant monitoring of the salt-water interface is necessary. The main approach to quantifying the amount of salinity is to measure the discharge and salt concentrations at gauging stations and compute the salt burden. Other approaches involve measuring with environmental tracers at high spatial resolution and employing dynamic simulation tools to interpret the results (Moran, 2009). One of the more popular methods to control saltwater intrusion is through the use of deep recharge wells. These wells create a high potentiometric surface, which allows for the pumping of groundwater below sea level landward of a groundwater ridge created. In some instances, barrier wells have been set up near the shore to pump out salt water and recharge a fresh water gradient toward the sea (De Breuck, 2008).

Two other significant influences on salinity include solute concentration from evapotranspiration and geochemical reactions of solutes by irrigation water with the minerals and gases present in the soil. Understanding the salinity sources and dynamics are the key to the development and evaluation of measures to mitigate the groundwater salinity (Moran, 2009). There are several scientific laws which play a factor in the salinity dilemma, especially when looking at agriculture (Alley and Taylor, 2001) including: (a) It is physically impossible to irrigate using salty water without some water, salt and nitrogen passing below the root zone; (b) Almost every time water is used, the released water has higher salt content than intake water, which contributes to the growth of the salinity problem; (c) The salt concentration out of the root zone is more concentrated than irrigation water; and (d) Chemicals in the soil strata below the root zone will be mobilized by flowing water. Hydrologic studies and water quality monitoring are essential to help better understand the movement and interaction of fresh water and salt water in the subsurface and determine the best course needed to manage saltwater intrusion. Potentiometric surface mapping of an aquifer can provide important information determining the direction of groundwater flow within a confined aquifer. The monitoring of well networks allows continuous observation of the saltwater interface. This is done to provide early warnings of saltwater intrusion.

Another important factor is the amount of precipitation an area receives and its effect on the depth of the water table. Water infiltrated into the groundwater is generally modeled as a quantity of flow which later appears in the stream as a baseflow (Amatya and Jha, 2011; Amatya et al., 2011; 2013; Jha, 2011). Groundwater levels will increase and decrease due to many different causes. The change in the water table level will occur over different time scales. Long-term fluctuations, which occur over long periods such as decades or centuries, can be produced by naturally occurring changes in climate and human activity such as changes in land usage, pumping, irrigation and induced infiltration (Healy and Cook, 2002). Seasonal fluctuations are more common in many areas due to the seasonality of evapotranspiration, precipitation and irrigation. Short-term water-table fluctuations are caused by rainfall, pumping, changes in the barometric-pressure or other phenomena. Long-duration, low-intensity precipitation events are not optimal because the slow, steady rate of water percolation to the water table may not be greater than or equal the rate of human caused drainage from the water table (Healy and Cook, 2002). One factor adversely affecting the groundwater water table is the destruction of wetlands. Kelly (2010) found that there was a time lag of several days between the time of precipitation and the increase of the ground water level. Also, the amount of water which would normally infiltrate into the groundwater was found to decrease mainly due to urbanization.

In conclusion, the problem that needs to be solved is how to get additional water without creating salt water intrusion which occurs when groundwater is pumped from aquifers that are in hydraulic connection with the ocean. The induced gradients cause the migration of salt water from the sea toward a well, making the freshwater well unusable. We hypothesize that a more informed decision on the sustainable use of groundwater resources can be made by determining the role of water salinity in the relationship of precipitation and water table depth. This study attempts to quantify this relationship by analyzing long-term data.

\section{MATERIALS AND METHODS}

\subsection{Precipitation Data}

The monthly precipitation data was acquired from the State Climate Office of North Carolina from their CRONOS Database. The data was obtained for the monitoring site at the Dare County Airport for the period between April 2007 and March 2011. The data is displayed in Table 1 and plotted graphically in Fig. 1. The monthly mean was calculated for each month based on the available measurements in five years. Figure 2 shows the 
comparison between the measured precipitation of each month and the computed monthly mean. The data was somewhat skewed due to 2007 having a severe drought and 2010 having a significant increase in rainfall.

\subsection{Groundwater Level and Salinity Data}

Groundwater level data was acquired from the United States Geological Service (USGS) website. The site chosen was USGS gage number 0208117839, located within the Alligator River National Wildlife Reserve, just off the Alligator River where it intersects with US Highway 64 in Tyrrell County in North Carolina. The data obtained was comprised of a three year average of daily measurements for the depth of the water table and the salinity of the aquifer at depths of 5 and 10 feet.
From this data, monthly averages were obtained for all three values (Fig. 3).

Some of the daily averages for the month of September seem glaringly high. One possible reason might have been due to hurricanes or tropical storms but the September precipitation data is only just slightly higher. Another potential causes could stem from the Alligator River flooding. It is difficult to tell without knowing which year the high measurements were taken. A monthly mean was calculated from the three year daily average for each month.

The other relevant data that was collected was the salinity of the unconfined aquifer measured by the USGS well. Figure 4 shows the three year daily mean of salinity at an aquifer depth of 5 feet and 10 feet.

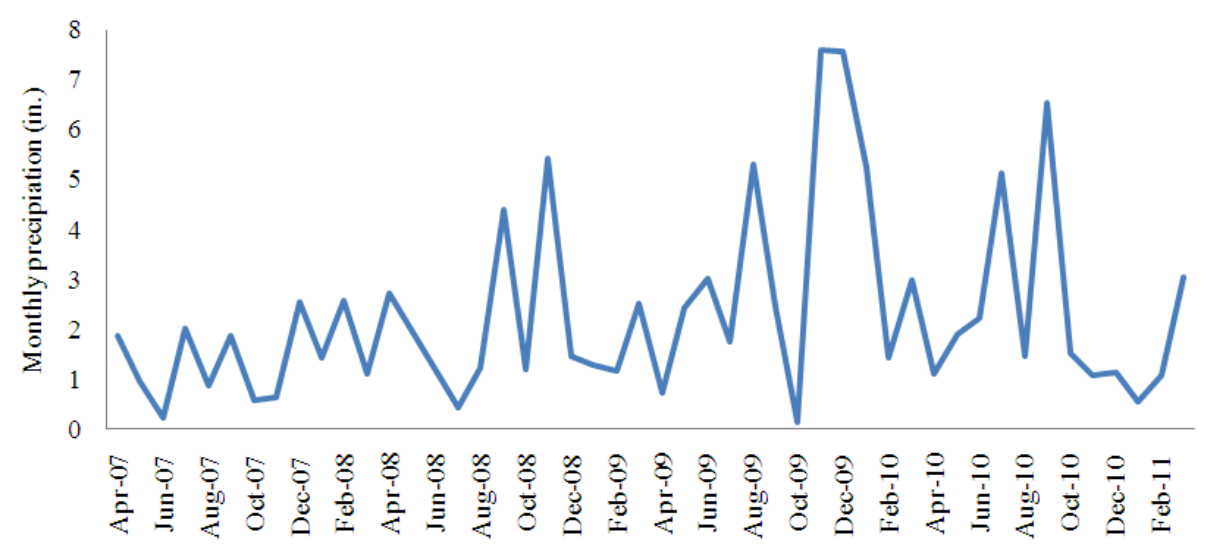

Fig. 1. Monthly precipitation measured at the Dare County Airport monitoring site in North Carolina

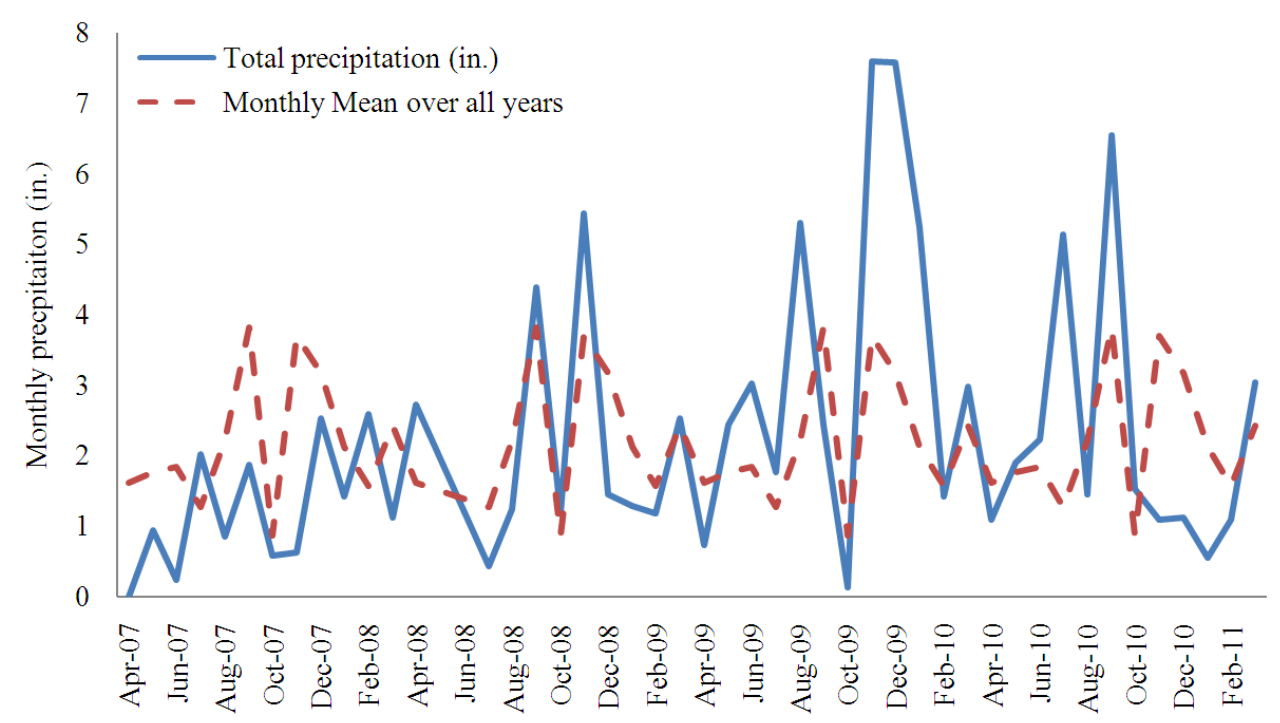

Fig. 2. Comparison between monthly precipitation and average monthly precipitation 


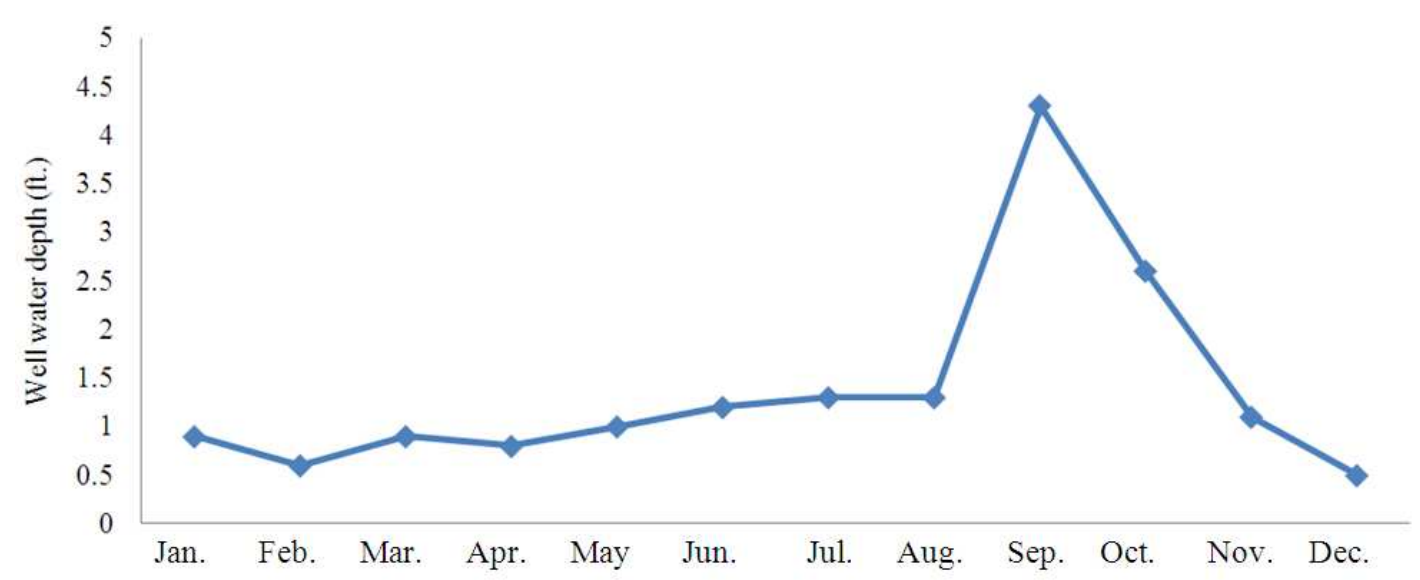

Fig. 3. Monthly mean well water depth

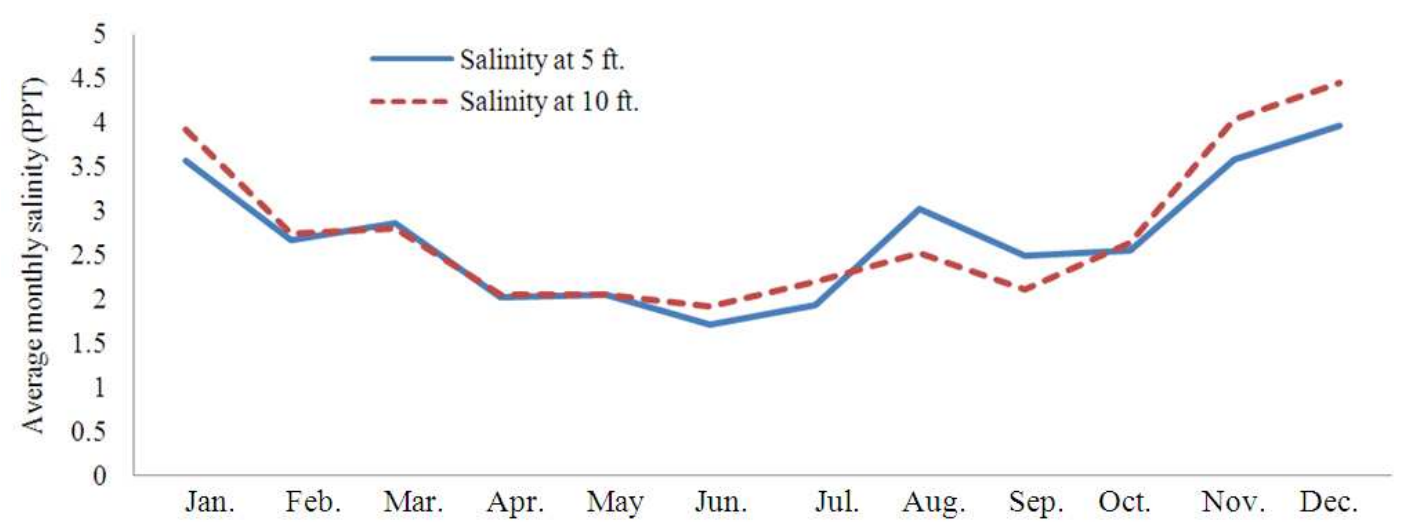

Fig. 4. Monthly average salinity in PPT at an aquifer depth of $5 \mathrm{ft}$. and $10 \mathrm{ft}$

Table 1. Monthly precipitation totals for the Dare County Airport monitoring site

\begin{tabular}{|c|c|c|c|c|c|c|}
\hline \multirow[b]{2}{*}{ Mon./Yr. } & \multicolumn{5}{|c|}{ Precipitation (in.) } & \multirow[b]{2}{*}{ Mean } \\
\hline & 2007 & 2008 & 2009 & 2010 & 2011 & \\
\hline Jan & - & 1.42 & 1.29 & 5.24 & 0.55 & 2.13 \\
\hline Feb & - & 2.59 & 1.18 & 1.42 & 1.09 & 1.57 \\
\hline Mar & - & 1.12 & 2.53 & 2.99 & 3.05 & 2.42 \\
\hline Apr & 1.86 & 2.73 & 0.73 & 1.10 & - & 1.61 \\
\hline May & 0.95 & - & 2.44 & 1.90 & - & 1.76 \\
\hline Jun & 0.24 & - & 3.03 & 2.23 & - & 1.83 \\
\hline Jul & 2.02 & 0.44 & 1.77 & 5.14 & - & 2.34 \\
\hline Aug & 0.86 & 1.24 & 5.30 & 1.46 & - & 2.22 \\
\hline Sep & 1.87 & 4.39 & 2.45 & 6.55 & - & 3.82 \\
\hline Oct & 0.59 & 1.19 & 0.14 & 1.53 & - & 0.86 \\
\hline Nov & 0.63 & 5.44 & 7.60 & 1.09 & - & 3.69 \\
\hline Dec & 2.54 & 1.46 & 7.58 & 1.13 & - & 3.18 \\
\hline
\end{tabular}

Salinity at different depth seems to fluctuate without a consistent pattern. This result is somewhat surprising as one would think that since salt water is denser than fresh water; higher concentrations of salt would reside at the 10 feet depth. However, in the higher temperature portions of the year, the salinity concentration is higher at the 5 feet depth. 


\section{RESULTS AND DISCUSSION}

\subsection{Precipitation versus Well Water Depth}

Figure 5 shows the monthly average well water depth as compared with the mean monthly precipitation. There does not seem to be a strong correlation between the amount of precipitation and the depth of the water table. The only time the two values seem to be in synch is during the months from October to November. The September data seems like an outlier on this graph. Perhaps a daily comparison would be more accurate and show a possible strong relationship with the actual lag time between precipitation and the depth of the water table. The only obstacle to this was the lack of daily data from the USGS groundwater monitoring well.

\subsection{Salinity versus Precipitation}

Figure 6 exhibits moderate correlation between the precipitation and salinity. Both are often increasing or decreasing at the same time. The short time period used to calculate the mean may be unduly influencing the relationship. Other potential cause may be due to infiltration from the precipitation leading to the dilution of the salt water. Other source of error could be the precipitation data, mean of which is sensitive to missing data or errors in measurement.

\subsection{Salinity versus Precipitation and Well Water Depth}

Figure 7 attempts a comparison of all data obtained to try and discern any additional relationships. It is apparent that no other inferences can be made from the data. Table 2 displays the results of a t-test.

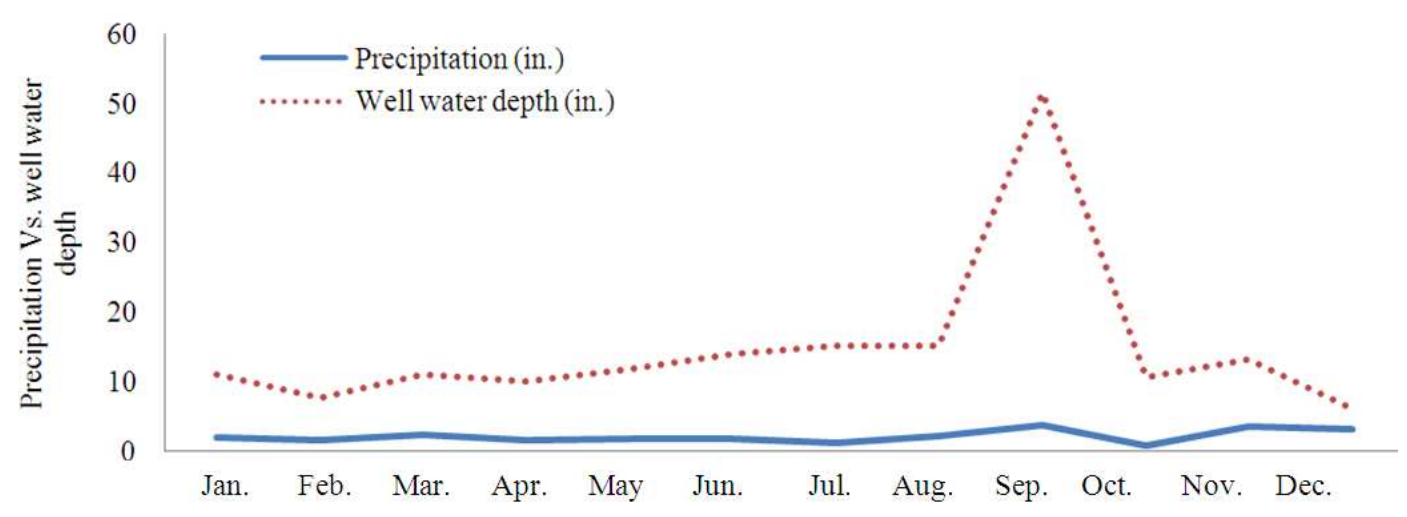

Fig. 5. Graphical representation of mean monthly precipitation and mean well depth

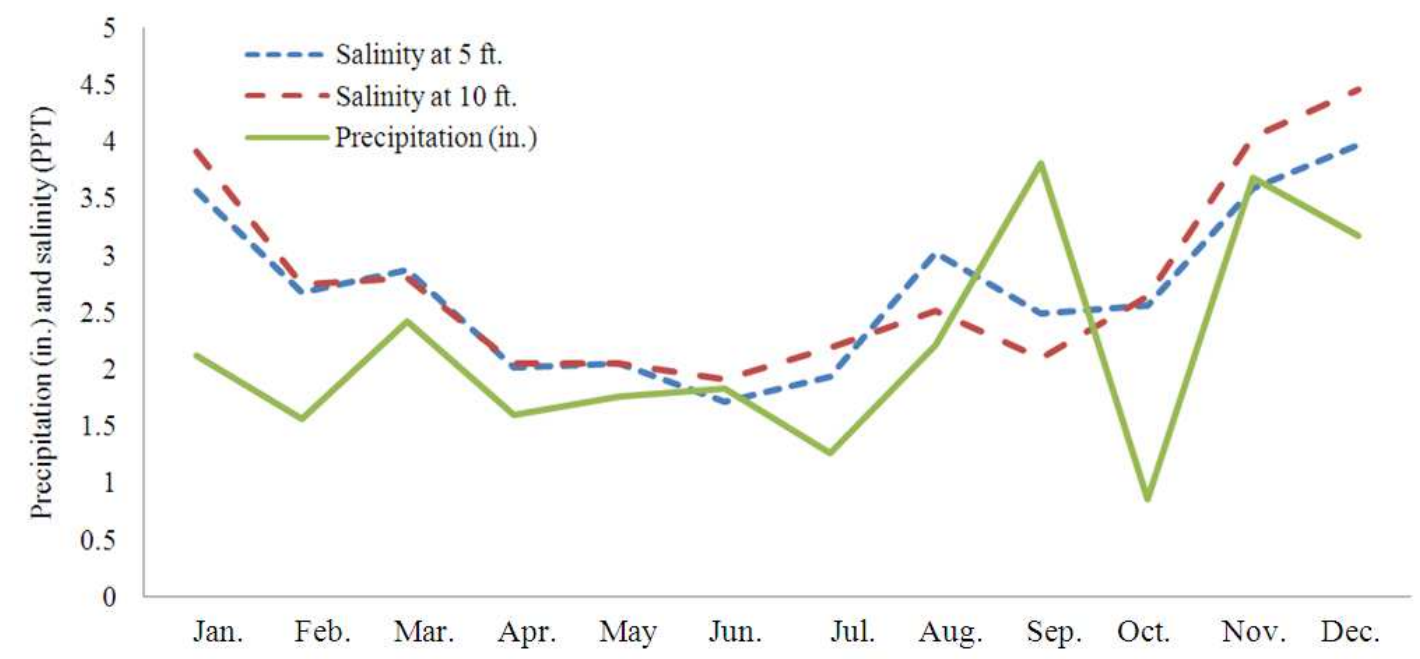

Fig. 6. Relationship between mean monthly precipitation and salinity 


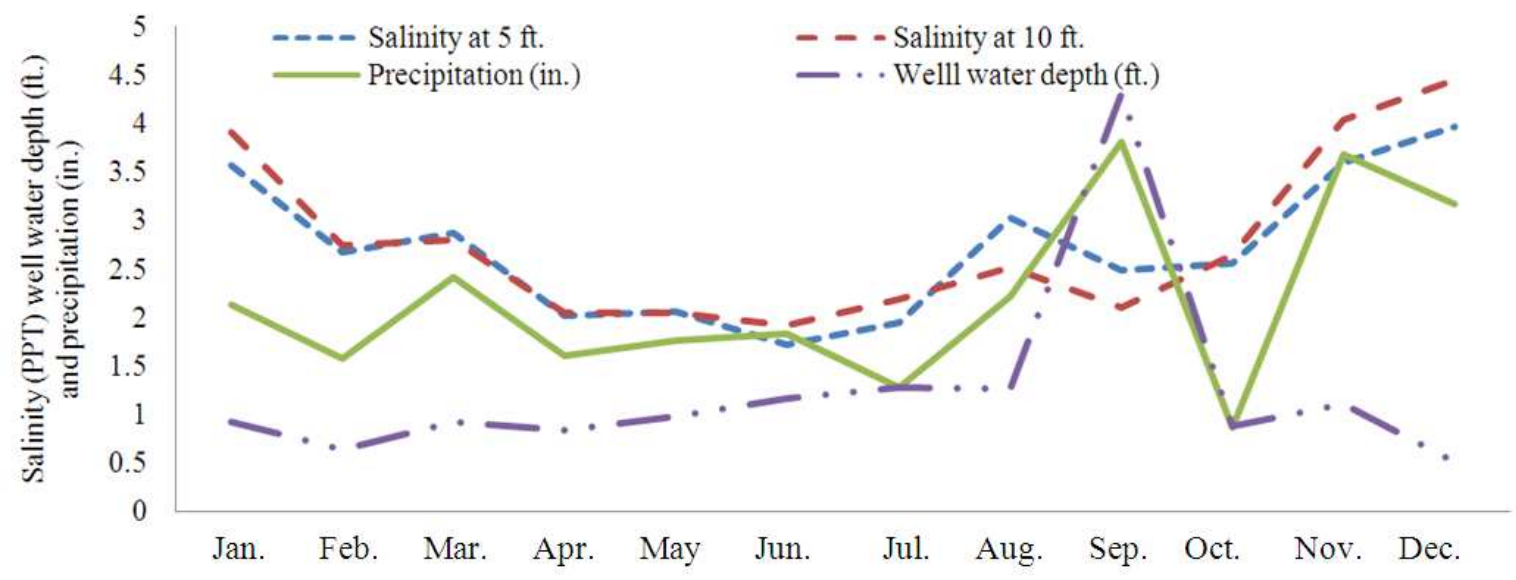

Fig. 7. Monthly mean values for all measurements obtained

Table 2. Results from t-test statistics

\begin{tabular}{lcclc}
\hline Month & Salinity at $5 \mathrm{ft}$. & Salinity at $10 \mathrm{ft}$. & Precipitation (in.) & Well water depth (ft.) \\
\hline Jan & 3.57 & 3.92 & 2.13 & 0.93 \\
Feb & 2.68 & 2.75 & 1.57 & 0.64 \\
Mar & 2.87 & 2.81 & 2.42 & 0.93 \\
Apr & 2.02 & 2.05 & 1.61 & 0.83 \\
May & 2.05 & 2.05 & 1.76 & 0.98 \\
Jun & 1.71 & 1.92 & 1.83 & 1.16 \\
Jul & 1.94 & 2.19 & 1.27 & 1.27 \\
Aug & 3.02 & 2.52 & 2.22 & 4.30 \\
Sep & 2.49 & 2.10 & 3.82 & 0.89 \\
Oct & 2.55 & 2.64 & 0.86 & 1.11 \\
Nov & 3.59 & 4.04 & 3.69 & 0.51 \\
Dec & 3.97 & 4.45 & 3.18 & 1.23 \\
Mean & 2.71 & 2.79 & 2.20 & 0.99 \\
Std. Dev. & 0.73 & 0.87 & 0.93 & 4.31 \\
Z Value & 12.89 & 11.06 & 8.16 & \\
\hline
\end{tabular}

The calculated $\mathrm{Z}$ values show a very close relationship between the average salinity at 5 and 10 feet. There is more of a correlation between the precipitation data than the depth of the water table.

\section{CONCLUSION}

This study attempts to relate groundwater salinity with well water depth and precipitation. A site in North Carolina was chosen for the case study. Relevant data were collected from respective sources such as USGS and NC Climatic Data Center. Data analysis identified the lack of a strong correlation between the water table depth and precipitation. A significant correlation was expected between the two with a brief lag time between the precipitation and the well water depth. Also, the salinity should have been more closely related to the precipitation.
The biggest influence on this disconnect was probably due to the lack of available daily data. A month is just too big of a time period to be able to detect subtle changes. Another reason the expected relations did not appear is that the USGS data was only obtainable via three year averages. Without knowing which values were obtained at what date and the circumstances surrounding the measurement, it is impossible to know which data to exclude as being too high or low due to error or other causes. The next step in this research could be to find a way to obtain the daily measurements needed either through early planning and gathering the precipitation data every 180 days and possibly through USGS well measurements at other locations nearby which could serve as a point of comparison. Overall, proper groundwater monitoring techniques and groundwater 
management combined with groundwater conservation are the best methods to keep saltwater intrusion under control and ensure sustained fresh water supplies for future generations.

\section{REFERENCES}

Alley, W.M. and C.J. Taylor, 2001. Groundwater level monitoring and the importance of long-term water level data. U.S. Geological Survey. pp: 12-17.

Amatya, D.M. and M.K. Jha, 2011a. Evaluating the SWAT model for a low-gradient forested watershed in coastal South Carolina. Trans. Am. Society Agric. Biol. Engineers, 54: 2151-2163.

Amatya, D.M., M.K. Jha, A. Edwards, T. Williams and D. Hitchcock, 2011b. SWAT-based streamflow and embayment modeling of karst-affected Chapel branch watershed, South Carolina. Trans. Am. Society Agric. Biol. Engineers, 54: 1311-1323.

Amatya, D.M., M.K. Jha, A. Edwards, T. Williams and D. Hitchcock, 2013. SWAT model prediction of phosphorus loading in a South Carolina Karst watershed with a downstream embayment. J. Environ. Protection, 4: 75-90. DOI: 10.4236/jep.2013.47A010
De Breuck, W., 2008. Hydrogeology of salt-water intrusion: Methods and instruments. Southwest Hydrology. pp: 24-25.

Healy, R.W. and P.G. Cook, 2002. Using groundwater levels to estimate recharge. Hydrogeol. J., 10: 91109. DOI: $10.1007 / \mathrm{s} 10040-001-0178-0$

Jha, M.K., 2011. Evaluating hydrologic response of an agricultural watershed for watershed analysis. Water, 3: 604-617. DOI: 10.3390/w3020604

Kelly, B.P., 2010. Relations Among river stage, rainfall, ground-water levels and stage at two missouri river flood plain wetlands. U.S. Geological Survey.

Montenegro, S.M., W.D. Costa, J.J.S.P. Cabral, A. Montenegro and E.S. de Lima et al., 2003. Monitoring time and spatial changes in groundwater salinity in the Recife Coastal Plain. Proceedings of the 2nd International Conference on Saltwater Intrusion and Coastal Aquifers Monitoring, Modeling and Management. Mar. 30-Apr. 2, Mérida, Yucatán, México, pp: 1-5.

Moran, J.E., 2009. Groundwater salinity: A groundwater dilemma. Hydro Visions, 18: 1-8.

Xue, Y., J. Wu, P. Liu, J. Wang and Q. Jiang et al., 1993. Groundwater: A study on sea-water intrusion in the coastal area of Laizhou Bay, China. Hydrochemical. Characterist., 31: 532-537. 